\section{Vol. 66, No. 26}

In the report "Tobacco Use in Top-Grossing Movies United States, 2010-2016," on page 683, the last sentence of the third paragraph of the Discussion should have read "During 2010-2016, approximately 24 states awarded approximately $\$ \mathbf{1 . 7}$ billion in public subsidies, such as tax credits, to productions of movies with tobacco incidents, including youth-rated movies. ${ }^{* *}$

\section{Vol. 66, No. 36}

The announcement "Childhood Cancer Awareness Month September 2017," on page 963, should have included the following as the third and last reference:

Oeffinger KC, Mertens AC, Sklar CA, et al.; Childhood Cancer Survivor Study. Chronic health conditions in adult survivors of childhood cancer. N Engl J Med 2006;355:1572-82. 